\title{
CALVINO E LEOPARDI: CONSONÂNCIAS E DISSONÂNCIAS SOBRE TRADUÇÃO
}

\author{
Andréia Guerini* \\ Tânia Mara Moysés**
}

\begin{abstract}
Resumo: Este artigo discute algumas relações entre as contribuições de Giacomo Leopardi (1798-1837) e Italo Calvino (1923-1985) aos Estudos de Tradução, através de ideias contidas em seus epistolários e em alguns ensaios de seus respectivos livros, Zibaldone di Pensieri (1817-1832) e Saggi (1945-1985), que demonstram o caráter de referência que o trinômio leopardiano "autor-tradutor-leitor" representa para o quadrinômio calviniano autor-editor-tradutor-leitor, para a tradução entendida como síntese entre fidelidade e liberdade. Palavras-chave: Literatura italiana; tradução; Calvino; Leopardi.
\end{abstract}

A admiração de Italo Calvino por Giacomo Leopardi, tão manifesta nas Lezioni americane: sei proposte per il prossimo millennio (2002) e em "Perché leggere i classici" (2001), é uma constante ao longo de sua vida. Trata-se de uma "influência" que Calvino confessa literalmente em seu epistolário. Na carta a Antonio Prete, datada de 10 de março de 1984, há menos de dois anos da morte, ao falar da resenha de Palomar, seu último livro,

* Universidade Federal de Santa Catarina.

** Doutoranda em Teoria Literária na Universidade Federal de Santa Catarina. 
diz: "Sono contento anche dei riferimenti leopardiani perché le Operette morali sono il libro da cui deriva tutto quello che scrivo."

Trata-se de um comentário autocrítico por parte do último Calvino, em seu período cósmico-antropomorfo, que, por si só, parece traduzir, ao mesmo tempo, o espírito da obra leopardiana e o título da referida resenha, ou seja, "Come il signor Palomar riuscì a diventare una galassia." Palomar e Lezioni americane: sei proposte per il prossimo millennio interligam-se em suas formas, respectivamente poética e ensaístico-crítica, "come le facce di una medesima medaglia", observa Asor Rosa, e essa conjunção constitui Le operette morali do século XX: "protese a scrutare l'orizzonte, come quelle leopardiane, dalla punta aguzza d'una vetta isolata, e al tempo stesso ancorate solidamente da un'infinità di gioghi e colline ad un retroterra sterminato."3

Poder-se-ia dizer que Palomar, homem do século XX, sentindo-se fragmentado pelo declínio das próprias certezas, diante da problemática do mundo pós-bélico, põe-se a perscrutar os astros. E, nesse movimento, tem um predecessor também em Leopardi que, para mitigar a ferida existencial, põe-se a indagar os motivos pelos quais "la terra vuol sapere dalla luna se ella abbia in effetto tutto ciò che le attribuiscono i fisici e antichi e moderni". ${ }^{4}$ No Dialogo della terra e della luna seu olhar de poeta e ensaísta,

\footnotetext{
${ }^{1}$ CALVINO. Lettere (1940-1985), p. 1.512. "Estou contente também pelas referências leopardianas porque Le operette morali são o livro do qual deriva tudo aquilo que escrevo." (Todas as traduções deste artigo são das autoras.)

2 "Como o senhor Palomar conseguiu tornar-se uma galáxia."

3 "Como as faces de uma mesma medalha." ASOR ROSA. Stile Calvino, p. 123 "Estendidas a perscrutar o horizonte, como as leopardianas, da ponta aguçada de um vértice isolado, mas, ao mesmo tempo, ancoradas solidamente por uma infinidade de cimos e colinas um território interno interminável."

${ }^{4}$ LEOPARDI. Dialogo della terra e della luna, p. 55-63. "A terra quer saber da lua se ela tem realmente tudo o que lhe atribuem os físicos antigos e modernos."
} 
perscrutador do vago e do indefinido, também busca analisar a natureza fragmentária do homem através do colóquio entre a terra e seu satélite.

Já dentre as muitas cartas da juventude do futuro autor de Palomar, destinadas a Eugenio Scalfari, cujos temas são principalmente os projetos de vida, observa-se a presença do poeta de "L'infinito", como na carta de 07 de março de 1942, em que Calvino revela sua profissão de fé:

L'illuso di via Bogino, il prigioniero del sogno di Villa Meridiana non ragiona così. Altro cuore batte sotto lo sterno carenato del pescatore di nuvole di Sangiovanni (...). Affermarsi (...) non vuol dire affermare un nome ed una persona. Vuol dire affermare se stesso con tutto quello che si ha dentro (...). E appunto in ciò sta la mia certezza: questo qualcosa non rappresenta l'oggi, rappresenta il domani. ${ }^{5}$

Leopardi vive em exílio forçado na casa paterna de Recanati, que, segundo Diafani, "si materializza in metafore carcerarie". ${ }^{6}$ Calvino, por outro lado, não sendo um "prisioneiro do sonho de Villa Meridiana", teve liberdade pessoal e saúde para sair de Sanremo e exprimir aos pais, e a quem quer que fosse, o desejo de cursar Letras, de escrever e publicar. Esse desejo se repete

${ }^{5}$ CALVINO. Lettere (1940-1985), p. 49. "O iludido da Rua Bogino, o prisioneiro do sonho de Villa Meridiana não raciocina assim. Outro coração bate sob o esterno carenado do pescador de nuvens de Sangiovanni (...). Afirmar-se (...) não quer dizer afirmar um nome ou uma pessoa. Quer dizer afirmar a si mesmo com tudo aquilo que se tem dentro (...). E exatamente nisso está a minha certeza: é algo que não representa o hoje, representa o amanhã."

6 DIAFANI. La "stanza silenziosa": studio sull'epistolario di Leopardi, p. 54."Materializa-se em metáforas carcerárias." 
em muitas cartas, embora consciente do "jogo tremendo" que é "pensar no infinito", ou seja, em seus sonhos de glória. ${ }^{7}$

Portanto, é importante notar que Calvino conheceu, antes do ensaísta, e seguindo toda uma tradição crítica, o poeta Leopardi. Esse movimento é importante para o entendimento da palavra como "substância de toda obra literária". E Calvino enfatiza o "quanto è stato importante l'aver avuto come primo orizzonte letterario fondamentale quello della poesia", como revela em longa carta de 02 de março de 1969 a Gianni Celati: “(...) come per noi che cominciamo a esercitare la nostra attenzione letteraria negli anni Quaranta -: è solo nella poesia che non ci sono trucchi, o almeno che i trucchi (tematici, topici) sono più difficili"; ${ }^{8}$ isto, a poesia, segundo Calvino, rejeita a afetação.

Se o interesse de Calvino pela poesia demonstra o seu reconhecimento pela lírica como o gênero por excelência, embora sendo, também por autodefinição, um "escritor de contos", isso pode decorrer não somente do fato de a poesia ter sido seu "horizonte fundamental", mas também das leituras de Leopardi.

Segundo o escritor de Recanati, os elementos da lírica também servirão à prosa, conforme indica em uma passagem do

\footnotetext{
${ }^{7}$ Leopardi encontra um meio de suprir a falta de contatos reais através da interlocução epistolar, sobretudo com o intelectual Pietro Giordani, a quem revela seu estado físico e moral (decorrente da doença, que lhe impõe o osso "esterno protuberante" - daí a alusão feita por Calvino -, e da solidão), como na carta de 14 de julho de 1817 - "se io fossi mio, le catene e le inferriate non mi terrebbero che volassi a voi" ["se eu fosse eu, as correntes e as grades não me impediriam de voar até o senhor"]. LEOPARDI. Epistolario, p. 124. L'infinito, composto em 1819, é o poema-símbolo do poeta Leopardi e uma das principais referências em Lezioni americane, a obra-testemunho da poética calviniana, publicada postumamente, em 1988.

${ }^{8}$ CALVINO. Lettere (1940-1985), p. 1.031. “(...) quanto foi importante ter tido como primeiro horizonte literário fundamental a poesia. (...) como para nós que começamos a exercitar a nossa atenção literária nos anos Quarenta -: é somente na poesia que não existem truques, ou pelo menos que os truques (temáticos, tópicos) são mais difíceis."
} 
Zibaldone, de 14 de setembro de 1821, para fugir também ao "desgosto da afetação":

Ma in sostanza, e per se stessa, la poesia non è legata al verso. E pure fuor del verso, gli ardimenti, le metafore, le immagini, i concetti, tutto bisogna che prenda un carattere più piano, se si vuole sfuggire il disgusto dell'affettazione, e il senso della sconvenienza di ciò che si chiama troppo poetico per la prosa, benchè il poetico, in tutta l'estensione del termine, non includa punto l'idea nè la necessità del verso, nè di veruna melodia. L'uomo potrebb'esser poeta caldissimo in prosa, senza veruna sconvenienza assoluta: e quella prosa, che sarebbe poesia, potrebbe senza nessuna sconvenienza assumere interissimamente il linguaggio, il modo, e tutti i possibili caratteri del poeta. ${ }^{9}$

É também no Zibaldone que Leopardi, graças à sua "ousadia e autonomia", atribui o estatuto de "primogênito de todos os gêneros" ao lírico, e se o Zibaldone não retém a atenção de Croce e Gramsci, o escritor e ensaísta Italo Calvino (em Lezioni americane) fará muitas referências não só ao poeta Leopardi, mas, também, ao prosador e, principalmente, ao ensaísta do Zibaldone. ${ }^{10}$

\footnotetext{
${ }^{9}$ LEOPARDI. Zibaldone di pensieri. "Mas, em última análise, a poesia não está ligada ao verso. $\mathrm{E}$, também fora do verso, as sutilezas, as metáforas, as imagens, os conceitos, tudo requer um caráter mais plano, quando se deseja fugir do desgosto da afetação e do senso de inconveniência do que se chama muito poético para a prosa, embora o poético, em toda a acepção do termo, não inclua de fato a ideia nem a necessidade do verso, nem de qualquer melodia. O homem poderia ser um grande poeta em prosa, sem qualquer inconveniência absoluta: e aquela prosa, que seria poesia, poderia, sem nenhuma inconveniência, assumir inteiramente a linguagem, o modo, e todos os possíveis atributos do poeta."
}

${ }^{10}$ GUERINI. Gênero e tradução no Zibaldone de Leopardi, p. 47-49; 111. 
Estabelecida, portanto, a ascendência clássica literária leopardiana de Calvino, este artigo é dedicado às relações, distantes mais de um século, entre suas ideias sobre tradução e as de Leopardi, contidas em seus respectivos epistolários e aprofundadas, respectivamente, em Saggi e noZibaldone di Pensieri.

Apesar de a tradução como foco teórico-prático ocupar um espaço importante na ampla gama de textos epistolares e ensaísticos de Calvino, a sua fortuna crítica ainda não tem explorado suas contribuições aos Estudos de Tradução, exceto em poucos e valiosos trabalhos, ${ }^{11}$ como Translation as Stylistic Evolution: Italo Calvino Creative Translator of Raymond Queneau (2009) de Federico Federici, em que a tradução calviniana de Les fleurs bleues em I fiori blu (1967) é contemplada em amplitude teórico-crítica, inclusive com o resgate do estudo de Silvia Taddei: "Calvino traduttore: I fiori blu" (1993). Nesse livro, Federici descredita a influência das ideias de Leopardi sobre o fazer tradutório de Calvino, por considerá-las não teóricas (e inclui Croce): "Calvino, like most Italian intellectuals, could not be entirely impassive to the reverential considerations that both Croce's thought and Leopardi's Zibaldone receive in Italy; it can

\footnotetext{
${ }^{11}$ Embora sem um foco teórico centrado exclusivamente na tradução, as Fiabe italiane foram objeto de variados estudos durante o Congresso "Inchiesta sulle fate: Italo Calvino e la fiaba", realizado em S. Giovanni Valdarno (Arezzo), em 1988, cujos ensaios foram organizados por Delia Frigessi. Em seu ensaio "L'esperienza di un piacere d'invenzione moderno. Italo Calvino e la fiaba" (2008), Teresa Guazzelli remete a alguns desses trabalhos, na análise das escolhas estilísticas de Calvino a partir de sua introdução a Fiabe italiane. Em língua portuguesa, no breve artigo "A tradução segundo Italo Calvino" (2005), Rita Ciotta Neves trata de aspectos da tradução de Les fleurs bleues de Queneau e afirma sua convicção, centrada no dito de Claudio Milanini, de que Il castelo dei destini crociati, Le città invisibili e Se una notte d'inverno un viaggiatore seriam recriações como sinônimo de tradução.
} 
be assumed that he knew their observations on translation, which are non-theoretical."12

Essa visão, equivocada a nosso ver, reflete o fato de que, muito admirado como poeta, mas ainda pouco estudado como ensaísta, Leopardi é raramente citado na história da tradução. Por consequência, a interligação entre suas ideias sobre tradução e as de Calvino tende a manter-se praticamente desconhecida.

Podemos dizer, ainda, que Leopardi trata com antecipação temas que seriam estudados por teóricos da tradução do século $\mathrm{XX}$. Isso permite afirmar que, enquanto profundo conhecedor da obra de Leopardi, não teria passado despercebida a Calvino a importância dessas ideias sob o ponto de vista teórico.

No Zibaldone há muitas páginas que tratam de tradução, a ponto de formar uma teoria da tradução. Leopardi considera a tradução literária uma arte, além de indicar, como qualidade para o tradutor, uma característica que é defeito para o escritor: a afetação, necessária ao tradutor, enquanto "responsável pela síntese" entre o próprio estilo e o estilo do autor estrangeiro. ${ }^{13}$

É importante notar que Leopardi viveu durante a chamada idade romântica, nos anos que assinalam a "primeira tentativa moderna de criar uma teoria da tradução", mediante a tese sobre as "traduções integrais" formulada por Goethe. Além disso, aqueles anos transcorrem em meio ao movimento contra as "belas infiéis" francesas ${ }^{14} \mathrm{e}$ aos debates entre classicistas e românticos acerca do ensaio "Sulla maniera e l'utilità delle traduzioni" de Madame de Staël, publicado no periódico Biblioteca Italiana (1816).

\footnotetext{
${ }^{12}$ FEDERICI. Translation as Stylistic Evolution: Italo Calvino Creative Translator of Raymond Queneau, p. 65. "Calvino, como muitos intelectuais italianos, não poderia estar inteiramente impassível às reverenciais considerações que o pensamento de Croce e o Zibaldone de Leopardi receberam na Itália; pode-se supor que ele conhecia suas observações sobre tradução, que não são teóricas."

${ }^{13}$ GUERINI. Gênero e tradução no Zibaldone de Leopardi, p. 131-133.

${ }^{14}$ MOUNIN. Teoria della traduzione, p. 54-55.
} 
No referido ensaio, a escritora francesa exorta os italianos a saírem do isolamento e do provincianismo da tradição literária clássica, abrindo-se à moderna literatura estrangeira (francesa, inglesa e, sobretudo, alemã), através também da tradução - ideia que Leopardi refuta por carta (18 de julho de 1816), como "rimedio [che] è come una dose d'oppio che differisce il dolore e ne lascia la cagione". ${ }^{15}$

Nessa carta, Leopardi ratifica antecipadamente as ideias que trocaria com o futuro "mestre" Giordani (tradutor do ensaio de Staël e entre os iniciadores da polêmica) sobre a perfeição da arte clássica - "Leggiamo e consideriamo e ruminiamo lungamente e maturamente gli scritti dei Greci maestri e dei Latini e degl'Italiani che han bellezze da bastare ad alimentarci per lo spazio di tre vite se ne avessimo" - e exorta os italianos ao cuidado com as imitações:

Leggete i Greci, i Latini, gl'Italiani, e lasciate da banda gli scrittori del Nord, e ove pure vogliate leggerli, se è possibile non gl'imitate, e se anco volete imitarli, non aprite più mai, ve ne scongiuro (...). Se mi è lecito, dirò ad esempio di Madama, parlare un momento di me, io come Talete ringraziava il Cielo per averlo fatto Greco, ringraziolo di cuore per avermi fatto Italiano, né vorrei dar la mia patria per un Regno, e ciò non per il potere d'Italia che niuno ne ha, né per il suo bel clima di cui poco mi cale né per le sue belle città di cui mi cale ancor meno, ma per lo ingegno degli Italiani, e per la maniera della italiana letteratura che è di tutte le letterature del mondo la più affine alla greca e latina, cioè a dire (parlo secondo la mia opinione, ed altri segua pure

\footnotetext{
${ }^{15}$ LEOPARDI. Lettera ai Sigg. compilatori della Biblioteca Italiana in risposta a quella di Mad. la baronessa di Staël Holstein ai medesimi."Remédio que é como uma dose de ópio que protela a dor e lhe deixa a causa."
} 
la sua) alla sola vera, perché la sola naturale, e in tutto vota d'affettazione. ${ }^{16}$

No ano seguinte, em uma carta a Giordani, datada de 29 de dezembro de 1817 , em sua solidão criativa e independente, Leopardi já antecipa aspectos da teoria da tradução que desenvolveria em seu Zibaldone. Ele fala, na carta, sobre os efeitos da atividade da tradução, colocando o leitor, aparentemente, diante de uma contraposição:

(...) mi pare d'essermi accorto che il tradurre così per esercizio vada veramente fatto innanzi al comporre, e o bisogni o giovi assai $\mathrm{p}$ [er] divenire insigne scrittore, ma che per divenire insigne traduttore convenga prima aver composto ed essere bravo scrittore, e che in somma una traduzione perfetta sia opera più tosto da vecchio che da giovane. ${ }^{17}$

${ }^{16}$ LEOPARDI. Lettera ai Sigg. compilatori della Biblioteca Italiana in risposta a quella di Mad. la baronessa di Staël Holstein ai medesimi. "Leiamos e consideremos e ruminemos longamente e maturamente os escritos dos Gregos e dos Latinos e dos Italianos que possuem belezas bastantes para alimentar-nos pelo espaço de três vidas se as tivéssemos (...). Leiam os Gregos, os Latinos, os Italianos, e deixem de lado os escritores do Norte, e, contudo, caso desejem lê-los, se for possível, não os imitem, e se desejam imitá-los, não revelem jamais, eu imploro (...). Se me é permitido (direi, a exemplo de Madame) falar um momento sobre mim, eu, como Tales dava graças aos Céus por tê-lo feito grego, agradeço-lhes de coração por ter-me feito italiano, nem gostaria de dar a minha pátria por um Reino, e isto não pelo poder da Itália que nenhum ela possui, nem pelo seu belo clima que pouco me importa, nem pelas suas belas cidades que me importam ainda menos, mas pelo engenho dos Italianos, e pela maneira da Literatura italiana que é de todas as literaturas do mundo a mais afim à grega e à latina, devo dizer (falo segundo a minha opinião, e os outros que sigam a sua própria), à única verdadeira, porque a única natural e em tudo isenta de afetação.”

${ }^{17}$ LEOPARDI. Epistolario, p. 172. “(...) parece que me dei conta de que o traduzir assim por exercício deve realmente preceder a escrita e é necessário ou muito útil para tornar-se insigne escritor; mas, para tornar-se insigne tradutor convém primeiramente ter escrito e ser um bom escritor, e que uma tradução perfeita, em suma, é obra mais da maturidade que da juventude." 
Essa contraposição talvez possa ser resolvida, sob o ponto de vista teórico, por meio de uma "pedagogia da tradução". Leopardi considera a atividade tradutória como um "exercício" na formação do escritor, desde que este traduza os clássicos gregos e latinos, como Homero, Virgílio e Horácio.

Essa é uma possível forma para tornar-se um bom escritor; mas Leopardi afirma que só traduz bem quem já é escritor maduro, pois domina a "técnica" de escrever. E os binômios tradutor-escritor e escritor-tradutor representam os fundamentos lançados por ele para a "relevância do traduzir", ${ }^{18}$ de onde é possível deduzir que nem todos passam pelas provas didáticas correspondentes, isto é, quando, no momento da tradução, falta-lhes um dos termos dos referidos binômios.

Quando Mounin reclama a dívida dos estudiosos de tradução, segundo ele ainda pendente em meados do século XX, em formular uma teoria da tradução, ${ }^{19}$ observa-se o desconhecimento do autor em relação ao trabalho de Leopardi, teórico da tradução já no século XIX. No entanto, Mounin considera o fato de aquele período se caracterizar tanto pela aglomeração de notável desenvolvimento da atividade prática da tradução ocorrida ao longo dos tempos quanto pela falta da contrapartida teórica que signifique uma síntese das inumeráveis opiniões e teorias referentes à própria experiência do traduzir.

Mas tudo indica, como se vê a seguir, que, apesar de muito importante, a leitura de Mounin não foi a primeira e única fonte de conhecimento de linguística e teoria da tradução por parte de Calvino, como afirma Federici, ${ }^{20}$ pois as páginas do Zibaldone foram fundamentais tanto para as reflexões de Calvino sobre os valores de Lezioni americane quanto sobre tradução, sobremodo

\footnotetext{
${ }^{18}$ GUERINI. Gênero e tradução no Zibaldone de Leopardi, p. 129.

${ }^{19}$ MOUNIN. Teoria della traduzione, p. 64.

${ }^{20}$ FEDERICI. Translation as Stylistic Evolution: Italo Calvino Creative Translator of Raymond Queneau, p. 65.
} 
porque a segunda metade do século XX assinala um período importante para os estudos científicos da tradução.

Tais estudos se desenvolveram, como observa Nergaard na introdução de Teorie contemporanee della traduzione (2002), por meio de "critérios metodológicos e rigorosos", sob os pontos de vista semiótico, literário-poético e filosófico; esses chamaram a atenção de "três gerações" de estudiosos dos três grandes campos de indagação teórica que entrelaçam literatura e tradução: a palavra, o texto e a cultura. ${ }^{21}$

Talvez sem a intenção precípua de teorizar, Calvino não deixa de se ocupar de aspectos de todos os três campos, enquanto representam partes essenciais de sua arte literária, pois estão vinculados também à matéria verbal com a qual trabalham os escritores.

Suas cartas revelam que as primeiras experiências de tradução se deram por incentivo e influência de Cesare Pavese: "Io ho cominciato un nuovo mestiere: il traduttore. Farò Lord Jim di Conrad per Einaudi. Il buffo è che so malissimo l'inglese, ma Pavese dice che ne basta di traduttori che non sanno scrivere in italiano e s'impegna di rivedermi le bucce", escreve em 19 de março de 1947 a Silvio Micheli. ${ }^{22}$ Observe-se que no caso de Calvino o "escritor maduro" é o guia, isto é, Pavese; e o foco no italiano, como língua de chegada, já é a centelha a iluminar-lhe a defesa da língua como núcleo da literatura nacional e componente principal de sua possível traduzibilidade como língua de partida.

Se Pavese claramente inseriu Calvino no mundo da tradução e reconheceu seu valor como escritor ao avalizar (com Natalia Ginzburg) a publicação de Il sentiero dei nidi di ragno

\footnotetext{
${ }^{21}$ NERGAARD. Teorie contemporanee della traduzione, p. 3-17.

${ }^{22}$ CALVINO. Lettere (1940-1985), p. 184. "Comecei um novo ofício: o tradutor. Traduzirei Lord Jim de Conrad para a Einaudi. O engraçado é que sei inglês muito mal, mas Pavese diz que basta de tradutores que não sabem escrever em italiano e se empenha na revisão de minhas escorregadelas."
} 
(1947), razão tem Bertone ao indicá-lo também como "il prosatore che più lo [Calvino] spinse sulla via dell'assorbimento del dialetto e-parallelamente - di oltrepassamento dell'impasse regionalistica". ${ }^{23}$ O jovem Calvino reconheceu-o como tal em uma resenha de 1947 de Il compagno: “(...) è anche importante: il superamento del regionalismo. Questo libro scopre i tratti comuni e il comune sapore italiano di città e genti profondamente diverse: un richiamo all'unità in tempi in cui ce n'è bisogno."24

Alguns anos depois, Calvino teve a oportunidade de arrostar o desafio de superar vários regionalismos, mantendo-lhes o sabor italiano, com um trabalho de fôlego em que "gli interessi antropologici ereditati da Pavese entrano nel cuore della creatività calviniana". ${ }^{25}$ Neste trabalho, reunimos as duas atividades principais de sua vida intelectual, isto é, as de escritor e editorcrítico: o projeto editorial de Fiabe italiane (1956).

Vale dizer também que, dentro de suas especificidades, a tradução das duzentas fábulas será reconhecida por sua contribuição para o esforço de unificação linguística da Itália no período pós-Segunda Guerra, como atesta a carta de 06 de junho de 1957 ao erudito Benvenuto Terracini:

(...) ho letto il suo saggio sul Trecento così ricco di spunti di reflessione critica anche per i non specialisti, e Le sono molto grato per quel che Lei dice della mia introduzione alle Fiabe. Tenevo molto al Suo Giudizio

\footnotetext{
${ }^{23}$ BERTONE. Italo Calvino: il castello della scrittura, p. 77. "O prosador que mais o impulsionou pelo caminho da absorção do dialeto e - paralelamente de superação do impasse regionalístico.”

${ }^{24}$ CALVINO. Il compagno, p. 1.212. “(...) é também importante: a superação do regionalismo. Este livro descobre os traços comuns e o sabor comum italiano de cidades e gentes profundamente diversas: um chamamento à unidade em tempos em que essa se faz necessária."

${ }^{25}$ PERRELLA. Calvino, p. 36. "Os interesses antropológicos herdados de Pavese entram no coração da criatividade calviniana."
} 
e sono molto contento di come Lei definisce e apprezza lo spirito del mio lavoro. Il trovarmi perfettamente in linea con l'Alighieri del De vulgari eloquentia m'ha molto sorpreso e inorgoglito. ${ }^{26}$

A surpresa de Calvino diante do ilustre elogio se justifica ainda mais se nos reportarmos ao que diz De Sanctis sobre o livro de Dante: "il libro De vulgari eloquio (sic) (...) è vera critica applicata ai tempi suoi, con giudizi nuovi e sensati (...). Voleva egli far del volgare quello che era il latino, non la lingua delle persone popolari, ma la lingua perpetua e incorruttibile degli uomini colti." 27

Portanto, o alinhamento mencionado por Terracini parece situar-se no aspecto linguístico e dentro de um projeto políticoliterário: Dante, em busca de uma língua literária que conjugasse esforços para a depuração dos dialetos por parte dos escritores de seu tempo, para a transformação do vulgar em língua literária; Calvino, em busca de traduzir as fábulas dos vários dialetos para o italiano (não mais o dialeto florentino, mas a língua nacional), mantendo-lhes, contudo, a essência secreta.

Por esse motivo, o dialeto está no foco das discussões sobre a questão linguística na literatura travadas entre Calvino e Pasolini, nos anos 1960. Essas discussões representam também o pano de fundo histórico para um amplo debate entre intelectuais, tais como

${ }^{26}$ CALVINO. Lettere (1940-1985), p. 492. “(...) li o seu ensaio sobre o século XIV tão rico de ideias para a reflexão crítica também pelos não especialistas, e lhe sou muito grato por aquilo que o senhor diz sobre a minha introdução às Fiabe. Esperava muito por seu parecer e estou muito contente pelo modo como o Senhor define e aprecia o espírito do meu trabalho. Encontrar-me perfeitamente alinhado com o Alighieri de De Vulgari eloquentia me deixou muito surpreso e envaidecido."

${ }^{27}$ DE SANCTIS. Storia della letteratura italiana, p. 204. "O livro De vulgari eloquio [1308] (...) é verdadeira crítica aplicada aos seus tempos, com julgamentos novos e sensatos (...). Ele deseja fazer do vulgar o que era o latim, não a língua do povo, mas a língua perpétua e incorruptível dos homens cultos." 
Vittorio Sereni, Elio Vittorini, Franco Fortini e outros, sempre através da imprensa.

Enquanto Pasolini considera a língua da unificação uma decorrência da vontade do poder político e da burguesia em destruir a cultura representada pelos dialetos, Calvino situa-a no cerne do processo de tradução, sobretudo em dois célebres ensaios: "L'italiano, una lingua tra le altre" e "L'antilingua", ambos de 1965. Nesses textos, tenta mostrar que qualquer língua e, neste caso, a italiana, deve ser essencialmente um instrumento de traduzibilidade. Esses ensaios são anunciados a Gino Montesanto, em carta de 27 de janeiro de 1965 , em que o uso do verbo "discutir" reflete a intensidade dos debates:

(...) la discussione sulla lingua mi appassiona molto. Finalmente si discute qualcosa di concreto. Quindi, dirò volentieri la mia nella vostra inchiesta (...). Ora ho già cominciato con un intervento che mi aveva chiesto Rago per "Rinascita" e uno per il "Giorno". Ma non ho affatto esaurito le cose da dire e più se ne discute più viene voglia di discuterne. ${ }^{28}$

No primeiro ensaio Calvino afirma “(...) la duttilità dell'italiano (questa lingua come di gomma con la quale pare di poter fare tutto quel che si vuole) ci permette di tradurre dalle altre lingue un pochino meglio di quanto non sia possibile in nessun'altra lingua". ${ }^{29}$ Essas ideias sobre a flexibilidade da língua

\footnotetext{
${ }^{28}$ CALVINO. Lettere (1940-1985), p. 847-848. "A discussão sobre a língua me apaixona muito. Finalmente se discute algo de concreto. Portanto, responderei de boa vontade a pesquisa (...). Agora já comecei com uma intervenção solicitada por Rago para 'Rinascita' e outra para il 'Giorno'. Mas não esgotei ainda as coisas por dizer, pois quanto mais se discute, mais vem a vontade de discutir."

${ }^{29}$ CALVINO. Litaliano, una lingua tra le altre lingue, p. 147. "A ductilidade do italiano (essa língua como de borracha com a qual parece possível fazer tudo o que se deseja) nos permite traduzir um pouquinho melhor que para qualquer outra língua."
} 
italiana para a tradução reportam a um fragmento do Zibaldone, de 1821, em que Leopardi eleva a língua italiana à matéria de tradução:

Ho detto che la lingua italiana è suscettibile di tutti gli stili, e ho detto che la conversazione francese non si può mantenere in italiano. (...). L'indole della nostra lingua è capace di leggerezza, spirito, brio, rapidità ec. come di gravità ec. è capace di esprimere tutte le nuances della vita sociale, ec. ma non è capace, come nessuna lingua lo fu, di un'indole forestiera. Così riguardo alle traduzioni. Ell'è capace di tutti i più disparati stili, ma conservando la sua indole, non già mutandola (...). E il pregio della lingua italiana consiste in ciò che la sua indole, senza perdersi, si può adattare a ogni sorta di stili. ${ }^{30}$

Entretanto, a constatação da flexibilidade da língua italiana apresenta dissonâncias entre as ideias dos dois escritores, pois Calvino considera tal vantagem "relativa e parcial", ao observar, ainda no ensaio "L'italiano, una lingua tra le altre lingue", que ao italiano faltavam códigos linguísticos populares que não descambassem no localismo e no dialeto.

Pode-se observar que, nesse momento, a divergência ocorre por conta do ponto de vista de observação de cada um deles sobre a língua italiana: para Leopardi, língua de chegada; para Calvino, língua de partida. O primeiro pensa no tradutor italiano;

\footnotetext{
${ }^{30}$ LEOPARDI. Zibaldone di pensieri. "Eu disse que a língua italiana é suscetível a todos os estilos, e disse que a conversação francesa não se pode manter em italiano. (...) A índole da nossa língua é capaz de leveza, espírito, verve, rapidez etc. Também de austeridade etc. É capaz de exprimir todas as nuanças da vida social, etc., mas não é capaz, como nenhuma língua o foi, de uma índole estrangeira. Também em relação às traduções. Ela é capaz de todos os mais disparatados estilos, mas conservando a sua índole, não já a modificando (...). E o mérito da língua italiana consiste nisso, pois a sua índole, sem se perder, pode adequar-se a todo tipo de estilos."
} 
o segundo, no tradutor estrangeiro, e o que une os dois, podemos dizer, é a qualidade estética do texto literário traduzido.

Segundo Calvino, o italiano criticado por Pasolini, quando utilizado na comunicação cultural, permite, frequentemente, que se resolvam os problemas de tradução de um dado código linguístico, ao passo que a ductilidade da língua italiana, aberta a vários influxos, mais que socorro, é obstáculo para o tradutor estrangeiro pela junção de vários códigos, consequência dos fatores históricos que a levaram a uma tardia homologação como língua nacional, em 1868: ${ }^{31}$

L'italiano è una lingua isolata, intraducibile. Una buona traduzione italiana di un libro straniero (riferiamoci al campo dove tutto è più difficile: la letteratura) può conservare un qualche saporino dell'originale; un libro di scrittore italiano tradotto il meglio possibile in qualsiasi lingua conserva del suo sapore originale una parte molto minore, o nulla del tutto. ${ }^{32}$

\footnotetext{
${ }^{31}$ Desde seu primeiro testemunho, em 960 d.C., com o Placito Capuano, o italiano sempre foi língua escrita e alvo de polêmica. O italiano ou dialeto florentino foi por séculos apenas língua literária, oficializado como língua nacional em 1868 com a nomeação pelo Ministro della Pubblica Istruzione, Emilio Broglio, de uma comissão, presidida por Alessandro Manzoni, que escolheu o dialeto florentino como língua nacional. Porém, somente com a grande onda migratória sul-norte no país, por conta do boom econômico do norte, após a Segunda Guerra, é que a língua passou a se difundida, graças também à chegada da televisão nos anos 1950. Para maiores informações ver: MIGLIORINI. Storia della lingua italiana, p. 90; 615.

${ }^{32}$ CALVINO. L'italiano, una lingua tra le altre lingue, p. 147. "O italiano é uma língua isolada, intraduzível. Uma boa tradução italiana de um livro estrangeiro (nos referimos ao campo onde tudo é mais difícil: a literatura) pode conservar algum pequeno sabor do original; um livro de escritor italiano traduzido o melhor possível em qualquer língua conserva uma parte muito menor do seu sabor original, ou nada do todo."
} 
Calvino considera que toda questão cultural se torna imediatamente também internacional e precisa ser verificada em uma escala mundial de pontos de referência, sem ferir o caráter de liberdade e criatividade próprio de cada língua. Não é necessário que o escritor escreva pensando em outra língua, mas, se escreve para comunicação é preciso que se dê conta do grau de traduzibilidade da sua linguagem, característica que se impõe para que o italiano possa ser uma "moderna língua europeia".

Isso não significa abandonar o caráter estético da tradução literária, tampouco situar o conceito de comunicação em Calvino na mesma esfera da "tradútica" criticada por Berman, ${ }^{33}$ pois o autor das futuras Lezioni americane já afirmava uma de suas propostas quando definia a exatidão como característica de seu ideal linguístico: "un italiano che sia il più possibile concreto e il più possibile preciso." ${ }^{34} \mathrm{O}$ autor também traçou suas previsões, quando afirmou no ensaio "L'antilingua" (1965) que toda língua se concentra em dois polos, um de imediata traduzibilidade em outras línguas e outro de destilação do que denomina "l'essenza più peculiare e segreta della lingua, intraducibile per eccellenza, e di cui saranno investiti istituti diversi come l'argot popolare e la creatività poetica della letteratura." 35

Cabe ao tradutor o papel de intermediário entre esses polos, o que não deixa de exigir dele o que Eco chama de "rispetto giuridico al detto altrui" ${ }^{36}$ Se atualmente os estudos de tradução discutem uma deontologia profissional, isso se reflete também

\footnotetext{
${ }^{33}$ BERMAN. A tradução e a letra ou o albergue do longínquo, p. 64.

${ }^{34}$ CALVINO. L'italiano, una lingua tra le altre lingue, p. 153. "Um italiano que seja o mais possível concreto e o mais possível preciso."

${ }^{35}$ CALVINO. L'antilingua, p. 158-159. "A essência mais peculiar e secreta da língua, intraduzível por excelência, e de que serão investidos institutos diferentes como o argot popular e a criatividade poética da literatura."

${ }^{36}$ ECO. Dire quasi la stessa cosa: esperienze di traduzione, p. 20. "Respeito jurídico pelo dito do outro."
} 
em Calvino, em carta de outubro de 1963 à revista Paragone, na qual exprime um protesto à crítica à tradução de Adriana Motti para Passage to India, de E. M. Forster, "per rendere giustizia a una delle nostre traduttrici migliori". ${ }^{37}$

Publicada também como ensaio, sob o título "Sul tradurre", a longa carta afirma a necessidade de uma crítica da tradução com responsabilidade técnica absoluta, o que supõe o respeito ao tradutor competente. Para isso, Calvino faz uma reflexão crítica tanto sobre as características técnicas, estilísticas e morais necessárias ao bom tradutor, quanto sobre a seriedade exigida ao modus operandi de um editor-colaborador de tradução.

$\mathrm{Na}$ verdade, o tradutor é para Calvino o terceiro agente na tarefa da tradução: ao trinômio "autor-tradutor-leitor", a síntese entre fidelidade e liberdade, [que] Leopardi apresenta [como] uma das mais fecundas contribuições para a tradutologia", ${ }^{38}$ ele propõe o quadrinômio autor-editor-tradutor-leitor.

Calvino tem a oportunidade de viver as quatro situações, diferentemente de Leopardi, pela vida literária marcada, sobretudo, pela atividade editorial na Einaudi, por 36 anos: exerce o papel de tradutor no próprio trabalho; vive como autor uma parceria crítico-colaborativa com seus tradutores; como editor, é colaborador e/ou revisor de traduções; como leitor, reconhece o peso das ações dos outros três agentes para a fruição da leitura, além de praticar a crítica literária, que inclui a crítica da tradução, o que era também feito por Leopardi quando ele se referia às traduções de clássicos gregos e latinos traduzidos ao italiano, como se pode observar em muitas de suas cartas.

Assim como Leopardi, Calvino também traduz, embora com menor ocorrência, mas não por isso menos intensamente, sobretudo obras advindas dos maiores expoentes do OULIPO -

\footnotetext{
${ }^{37}$ CALVINO. Lettere (1940-1985), p. 756. "Para render justiça a uma de nossas melhores tradutoras." CALVINO. Sul tradurre. In: Saggi, v. II, p. 1.776-1.786.

${ }^{38}$ GUERINI. Gênero e tradução no Zibaldone de Leopardi, p. 152.
} 
Ouvroir de Littérature Potentielle, de cujas experimentações matemático-literárias nasce sua própria narrativa combinatória. De Georges Perec, traduz Petit abécédaire illustré (1969). De Raymond Queneau, entre outras, Les fleurs bleues (1965).

Vale dizer também que as possibilidades de reflexão sobre os conteúdos teóricos implícitos na introdução de Calvino à sua tradução I fiori blu (1967) permitem a ele e ao leitor uma análise sob o ponto de vista da relação não resolvida entre tradutor e autor, diante das dificuldades de um e das expectativas do outro (evidentemente quando ainda vivo), como explica a Franco Quadri, em carta de 14 de abril de 1965: "La mia scrittura è ben lontana dalla complessità di Queneau, ma quando non ho l'occasione ed il tempo di spiegare al traduttore quello che ho messo in ogni frase (cioè, sempre: mi è riuscito di farlo solo una volta) vengo tradotto solo diciamo al 45\%."39

Em 1976, Calvino traduz Petit abécédaire illustré, de Georges Perec. A chave de cada um dos 16 textos narrativos equivale semanticamente a outro texto de poucas sílabas, o qual deve equivaler foneticamente à sucessão de uma consoante com as cinco vogais, como em $b a-b e-b i-b o-b u$, e assim por diante, para todas as consoantes do alfabeto.

Diante do desafio da intraduzibilidade, Calvino o converte no Piccolo sillabario illustrato através da equivalência em 19 textos, valendo-se também de minúsculas palavras estrangeiras, como sutilezas de outras línguas dentro do contexto italiano. Nesse caso, a equivalência interlinguística não é textual, mas por palavra, tema que Leopardi discute no Zibaldone quando encontra meios para resolver as dificuldades da equivalência, através do conhecimento de mais línguas, o que muitas vezes facilita a capacidade expressiva.

${ }^{39}$ CALVINO. Lettere (1940-1985), p. 865-866. "A minha escrita está bem distante da complexidade de Queneau, mas quando não tenho ocasião e tempo de explicar ao tradutor o que coloquei em cada frase (isto é, sempre: consegui fazê-lo só uma vez) sou traduzido, digamos, somente em 45\%." 
Por conhecer as dificuldades de traduzir, Calvino apresenta-se muito zeloso por seus escritos, estabelecendo uma parceria crítico-colaborativa com seus tradutores. Não se abstém de correções, ao tempo que se revela visível e exato ao responderlhes sobre as dúvidas no momento da tradução, como atestam várias cartas, inclusive a tradutores para o russo e o hebraico.

Calvino demonstra também a relação possível com tradutores da mesma obra em outras línguas, como ocorre durante sua colaboração de cinco anos com a tradução de Petite cosmogonie portative (1950), de Queneau, que virá à luz na tradução italiana de Sergio Solmi, Piccola cosmogonia portatile (1982), testemunhada passo a passo na cronologia epistolar.

Em carta de 07 de março de 1978, Calvino revela a Solmi uma tendência a encontrar o equilíbrio entre o poema original e sua tradução, ou seja, com foco no texto de chegada, para que pareça italiano, mas fiel, dentro do possível, à intenção do texto original:

(...) la tenuta poetica della traduzione, la bellezza dei versi, la spontaneità con cui sembrano nati dalla tradizione ital., la dimensione lucreziana che hai saputo rendere sono tali che anche se resteranno molti problemi non risolti, ne verrà fuori un libro straordinario. ${ }^{40}$

Em suas ações no campo da tradução, Calvino parece repetir um objetivo que é de Leopardi, dentro da ideia de que "uma boa tradução é aquela que consegue conservar o caráter estrangeiro e nacional ao mesmo tempo". ${ }^{41}$ Suas escolhas entre "estrangeirizar" (como em Schleiermacher, Benjamin, Venuti) e

${ }^{40}$ CALVINO. Lettere (1940-1985), p. 1.369. "A capacidade poética da tradução, a beleza dos versos, a espontaneidade que os fazem parecer nascidos da tradição italiana, a dimensão lucreciana que você soube traduzir são tais que, mesmo se restarem muitos problemas não resolvidos, virà à luz um livro extraordinário."

${ }^{41}$ GUERINI. Gênero e tradução no Zibaldone de Leopardi, p. 151. 
"domesticar" se resolvem na possibilidade de harmonia entre as duas opções em sentido amplo (como em Dryden, Pound e Borges).

Exemplo de seu ativo trabalho de revisor de traduções (Melville, Queneau, Fourier, Henry James) é a crítica de Calvino na carta ao tradutor uruguaio Umberto Bonetti, de 07 de abril de 1972, sobre o conto Las Hortensias de Felisberto Hernández:

Ho riveduto il primo dei racconti (...) e m'è costato una settimana di lavoro. La sua traduzione non contiene quasi nessun errore materiale, ma è quasi una traduzione letterale, lontana dalla disinvoltura indispensabile per uno scrittore come questo (...) e pensando a quel che mi aspetta ancora, non so proprio quando troverò il tempo di continuare la revisione. La pubblicazione di Felisberto non si profila certo come prossima (...). Ho guardato anche la prefazione (...) e lì mi pare che proprio non è venuto fuori niente, come una fotografia non riuscita. ${ }^{42}$

Observa-se aqui a importância da tradução como modo e meio de apresentação do autor estrangeiro ao leitorado italiano, cuja recepção se dá inclusive através dos ensaios-críticos (em forma de introduções, prefácios e posfácios) sobre as obras traduzidas, intervenções que Calvino também realiza, segundo a linha de tradição crítica igualmente exercida por Leopardi nas suas traduções de autores gregos e latinos.

Isso demonstra, mais uma vez, que Leopardi, além de estar à frente de seu tempo, é uma referência para Calvino, inclusive

${ }^{42}$ CALVINO. Lettere (1940-1985), p. 1.159-1.160. "Revisei o primeiro dos contos (...) o que levou uma semana de trabalho. A sua tradução não apresenta quase nenhum erro material, mas é quase uma tradução literal, distante da desenvoltura indispensável para um escritor como esse (...) e pensando no que ainda me espera, não sei mesmo quando encontrarei tempo para continuar a revisão. A publicação de Felisberto não se delineia como próxima. (...). Olhei também o prefácio (...) e dali parece que não saiu nada, como uma fotografia não revelada." 
no ensaio "Tradurre è il vero modo di leggere un testo" cujo título já contém a sua definição de tradução, formulada ao longo da criação literária e do trabalho editorial na Einaudi, enquanto a almeja também como matéria de estudos acadêmicos.

Coincidentemente, a partir do artigo "The name and nature of translation studies" (1972), de James S. Holmes, a matéria sempre nova da tradução será mapeada como a disciplina acadêmica dos Estudos da Tradução (ET), que, aberta à interdisciplinaridade, passa a ter seu espaço próprio nas universidades.

Como uma conquista para os dias atuais, podemos destacar que os ambientes "più istituzionali (...) con la nascita di corsi universitari in teoria della traduzione o translation studies, di pubblicazioni e studi, di conferenze e seminari" ${ }^{44}$ são hoje uma realidade a possibilitar o reconhecimento do trabalho de intelectuais como Leopardi e Calvino como epistológrafos e ensaístas, em prol da tradução.

Riassunto: Questo articolo intende approfondire la presenza di alcune relazioni intercorrenti fra i contributi degli scrittori italiani Giacomo Leopardi (1798-1837) e Italo Calvino (1923-1985) agli Studi sulla Traduzione, partendo da idee presentate nei loro epistolari e in alcuni saggi dei rispettivi libri Zibaldone di pensieri (1817-1832) e Saggi (1945-1985). Tali idee attestano quanto il trinomio leopardiano "autore-traduttorelettore" rappresenti per la concezione del quadrinomio calviniano "autore-editore-traduttore-lettore" ai fini della traduzione intesa come sintesi tra fedeltà e libertà.

Parole chiave: Letteratura italiana; traduzione; Calvino; Leopardi.

\footnotetext{
${ }^{43}$ ["Traduzir é o verdadeiro modo de ler um texto".]

${ }^{44}$ NERGAARD. Teorie contemporanee della traduzione, p. 10-13. "Mais institucionais (...) com o nascimento de cursos universitários em teoria da tradução ou Estudos da Tradução, de publicações e pesquisas, de conferências e seminários."
} 


\section{REFERÊNCIAS}

ASOR ROSA, Alberto. Stile Calvino.Torino: Einaudi, 2001.

BERMAN, Antoine. A tradução e a letra ou O albergue do longínquo. Trad. Marie-Hélène Catherine Torres, Mauri Furlan, Andréia Guerini. Rio de janeiro: 7 Letras/PGET, 2007.

BERTONE, Giorgio. Italo Calvino: Il castello della scrittura. Torino: Einaudi, 1994.

CALVINO, Italo. Lettere (1940-1985). A cura di Luca Baranelli. Introduzione di Claudio Milanini. 2. ed. Milano: Mondadori, 2001.

CALVINO, Italo. Perché leggere i classici. In: . Saggi (1945-1985).

A cura di Mario Barenghi. Introduzione di Mario Barenghi. 3. ed. Milano: Mondadori, 2001. p. 1.816-1.824. v. II.

CALVINO, Italo. Il compagno. In: . Saggi (1945-1985). A cura di Mario Barenghi. Introduzione di Mario Barenghi. 3. ed. Milano: Mondadori, 2001. p. 1209-1212. v. I.

CALVINO, Italo. L'italiano, una lingua tra le altre lingue. In: . Saggi (1945-1985). A cura di Mario Barenghi. Introduzione di Mario Barenghi. 3. ed. Milano: Mondadori, 2001. p. 146-153. v. I.

CALVINO, Italo. L'antilingua. In: . Saggi (1945-1985). A cura di Mario Barenghi. Introduzione di Mario Barenghi. 3. ed. Milano: Mondadori, 2001. p. 154-159. v. I

CALVINO, Italo. Tradurre è il vero modo di leggere un testo In: Saggi (1945-1985). A cura di Mario Barenghi. Introduzione di Mario Barenghi. 3. ed.. Milano: Mondadori, 2001. p. 1825-1831. v. II.

CALVINO, Italo. Lezioni americane: sei proposte per il prossimo millennio. Milano: The Estate of Italo Calvino e Mondadori, 2002.

DE SANCTIS, Francesco. Storia della letteratura italiana. Introduzione di René Wellek. 2. ed. Milano: Bur Rizzoli, 2009.

DIAFANI. Laura. La "stanza silenziosa": studio sull'epistolario di Leopardi. Firenze: Le Lettere, 2000.

ECO, Umberto. Dire quasi la stessa cosa: esperienze di traduzione. Milano: Bompiani, 2003. 
FEDERICI, Federico. Translation as Stylistic Evolution: Italo Calvino Creative Translator of Raymond Queneau. Amsterdam- New York: Rodopi, 2009.

GUERINI, Andréia. Gênero e tradução no Zibaldone de Leopardi. São Paulo: Edusp; Florianópolis: UFSC/PGET, 2007.

LEOPARDI, Giacomo. Zibaldone di pensieri. Disponível em: < http:// www.leopardi.it/zibaldone. php >. Acesso em: 2 mar. 2010.

LEOPARDI, Giacomo. Lettera ai Sigg. compilatori della Biblioteca Italiana in risposta a quella di Mad. la baronessa di Staël Holstein ai medesimi. Disponível em: < http://www.bibliotecaitaliana.it/xtf/ view?docId = bibit $000789 /$ bibit $000789 . \times m 1 \& \mathrm{chunk} . \mathrm{id}=$ d4972e127\&toc.id=\&brand=default $>$. Acesso em: 2 mar. 2010.

LEOPARDI, Giacomo. Dialogo della terra e della luna. In: Le prose morali. A cura di Ildebrando Della Giovanna. Presentazione di Giuseppe de Robertis. Firenze: Sansoni, 1957. p. 55-63.

LEOPARDI, Giacomo. Epistolario. A cura di Franco Brioschi e Patrizia Landi. Recanati: Bollati Boringhieri, 1998. v. I.

LEOPARDI, Giacomo. Zibaldone di pensieri. Disponível em: <http:// www.leopardi.it/zibaldone.php>. Acesso em: 2 mar. 2010.

LEOPARDI, Giacomo. Lettera ai Sigg. compilatori della Biblioteca Italiana in risposta a quella di Mad. la baronessa di Staël Holstein ai medesimi. Biblioteca Italiana. Disponível em: < http://www.biblioteca italiana.it/xtf/view?docId = bibit000789/bibit000789.xml\&chunk.id $=$ d4972e127\&toc.id $=\&$ brand $=$ default $>$. Acesso em: 2 mar. 2010.

MIGLIORINI, Bruno. Storia della lingua italiana. 10. ed. Milano: Bompiani, 2002.

MOUNIN, Georges. Teoria della traduzione. Traduzione di Stefania Morganti. Torino: Einaudi, 1965.

NERGAARD, Siri (a cura di). Teorie contemporanee della traduzione. 2. ed. Milano: Bompiani, 2002.

PERRELLA, Silvio. Calvino. Roma/Bari: Laterza, 1999. 